\title{
AUTOMATIC SEGMENTATION AND CLASSIFICATION OF BRAIN TUMOR USING DEEP LEARNING
}

\author{
K.Ganga Durga Prasad, A.J.N.Murthy, G.Narasimha, New Sinha \\ $1 \mathrm{~V} / \mathrm{II}, \mathrm{B}$. Tech. \\ Department of Electronics and Communication Engineering, \\ Godavari Institute of Engineering \& Technology (A), Rajahmundry, Andhra Pradesh, India.
}

\begin{abstract}
The brain tumors, are the maximum not unusual place and threatening disease, main to a totally quick lifestyles of their maximum grade. Thus, remedy making plans is a key level to enhance the lifestyles of sufferers. Normally, distinct photo strategies which includes CT, MRI and ultrasound photo are used to hit upon the tumor in a brain. on this approach MRI photos are used to diagnose brain tumor guide type of tumor vs non-tumor is a tough challenge for radiologosts. we gift an approach for detection and type of tumors with inside the brain. The computerized brain tumor type could be very hard challenge in brain tumor. In this approach, computerized brain tumor detection is executedwith the aid of usingthe use of Convolutional Neural Networks (CNN) type.Our proposed automation gadgetcould take an MRI and examine it to locate bengin (non-cancerous) or malignant (cancerous).
\end{abstract}

\section{key Terms - CT, MRI, Convolutional Neural Networks.}

\section{INTRODUCTION}

The area of clinical imaging is gaining significance with an growth with inside the call for automated, reliable, rapid and greenanalysisthat can offer perception to the photo higher than human eyes. Brain tumor is the second onemainmotive for most cancers-associated deaths in guys in age 20 to 39 and $5^{\text {th }}$ main motive most cancers amongst ladies in equal age group. Brain tumors are painful and canbring about numerous illnesses if now no longer cured properly. Diagnosis of tumor is a totallycriticalelement in its remedy. Identification performs an critical element with inside the analysis of benign and malignant tumors. A top purpose in the back of an growth with inside therange of most cancerssufferersinternational is the lack of understandingcloser toremedy of a tumor in its early stages. This paper discusses such an set of rules that could tell the consumer approximately information of tumor the use of simple photo processing strategies. These strategies encompass noise elimination and polishing of the photo along side simple morphological features, erosion and dilation, to achieve the history. Subtraction of history and its bad from distinct units of photos consequences in extracted tumor photo. Plotting contour and c-label of the tumor and its boundary presents us with data associated with the tumor that could assist in a higher visualization in diagnosing cases.
This procedure allows in figuring out the length, form and role of the tumor. It allows the clinical body of workers in addition to the affected person to recognize the seriousness of the tumor with the assistof various colorlabeling for distinctranges of elevation. A GUI for the contour of tumor and its boundary can offer data to the clinical body of workers on click on of consumer desire buttons.

\section{LITERATURE SURVEY}

In latest years, photo processing has carried out to proceduresnap shots in scientific stream, in coordinating mobileular identification. S. Mokhlel in 2012 offeredsome distinguishing evidence advances, inclusive of fragmenting snap shots to extricate the object from the inspirationthru the edge. This detailturned intooffered with the 'Gabor channel' with the intention to accomplish greater association into malignant increase cells. H. G. Zadeh in 2013 proposed in addition advances, that is image extraction and department of snap shots for diagnosing malignancy cells. The Gaussian smoothing concept turned into offered as a keeping apart purpose, beyond to making use of the 'Quick Fourier Transform' (FFT). AI for tumor discovery: 'NN', 'Fluffy C-signify' calculations turned intooffered for the recognizable evidence of tumorous cells. This takes decrease computational time but the precision moreoverdecrease. X. Chen affords great checking innovation in 2014. Be that because it may, this innovation is becomingonly for the complicatedimprovement of greatdesire. From the formerly cited strategies and using of advances, on this exam paper we centre across the recognizable evidence of thoughts tumor using image coping with procedures.

\section{EXISTING TECHNIQUES}

Existing solution of extraction of brain tumor from CT testphotos tumor element is detected from the CT test of the retina. The gadget tell the consumer approximately information of tumor the use of simple photo processing strategies. The strategiesencompass noise elimination and polishing of the photoalong side simple morphological features, erosion and dilation, to achieve the history. Subtraction of history and its bad from distinctunits of photos consequences in extracted tumor photo. 


\section{PROPOSED TECHNIQUES}

The human brain is modeled with the aid of using the use of layout and implementation of neural community. The neural community is specially used for vector quantization, approximation, information clustering, sample matching, optimization features and typestrategies. The neural communityis split into 3 kinds primarily based totally on their interconnections. Three kind neural networks are comments, feed ahead and recurrent community. The Feed Forward Neural community is in addition divided into unmarried layer community and multilayer community. In the unmarried layer community, the hidden layer isn'toffered. But it consists of handiest enter and output layer. However, the multilayer includes enter layer, hidden layer and output layer. The closed loop primarily based totallycomments community is known as recurrent community. In the everyday neural community, photocan't scalable. But in convolution neural community, photo can scalable (i.e) it's going to take 3-denterextent to 3-d output extent (length, width, height).The Convolution Neural Network (CNN) includesenter layer, convolution layer, Rectified Linear Unit (ReLU) layer, pooling layer and absolutelylinked layer. In the convolution layer, the given enterphoto is separated into numerous small regions. Element smart activation feature is done in ReLU layer. Pooling layer is optional. We can use or skip. However the pooling layer ismainly used for down sampling. In the very last layer (i.e) absolutelylinked layer is used to generate the magnificencerating or label rating fee primarily based totally at the chance in-among zero to 1 .

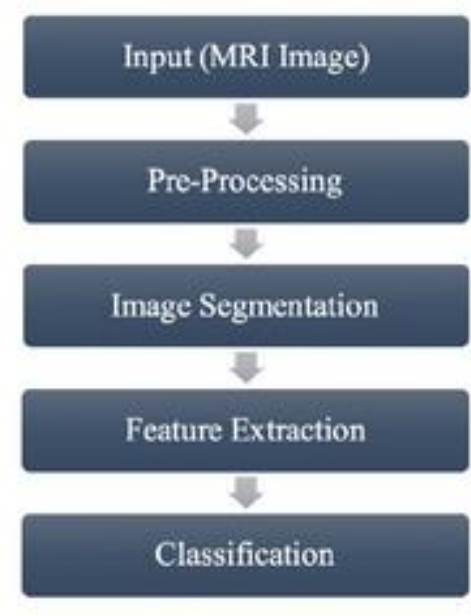

Fig 1.methodology

The block diagram of brain tumor type primarily based totally on convolution neural community is proven in fig. 1. The CNN primarily based totallybrain tumor typeis split into levels which includes schooling and trying outlevels. The range of photosis split into distinctclasswith the aid of usingthe use of labels callwhich includes tumor and non-tumor brainphoto etc. In the schooling phase, preprocessing, function exaction and type with Loss feature is carried out to make a prediction version. Initially, label the schoolingphoto set. In the preprocessing photo resizing is carried out to alternatelength of the photo. The loss feature is calculated with the aid of usingthe use of gradient descent set of rules.

The uncooked image pixel is mapping with magnificence ratings with the aid of using the use of a ratingfeature. The great of unique set of parameters is measured with the aid of using loss feature. It is primarily based totally on how properly the brought on ratings authorised with the floor reality labels with inside the schooling information. The loss feature calculation could be verycriticalto enhance the accuracy. If the loss feature is high, while the accuracy is low. Similarly, the accuracy is high, while the loss feature is low. The gradient fee is calculated for loss feature to compute gradient descent set of rules. Repeatly examine the gradient fee to compute the gradient of loss feature.

\section{RESULTS}

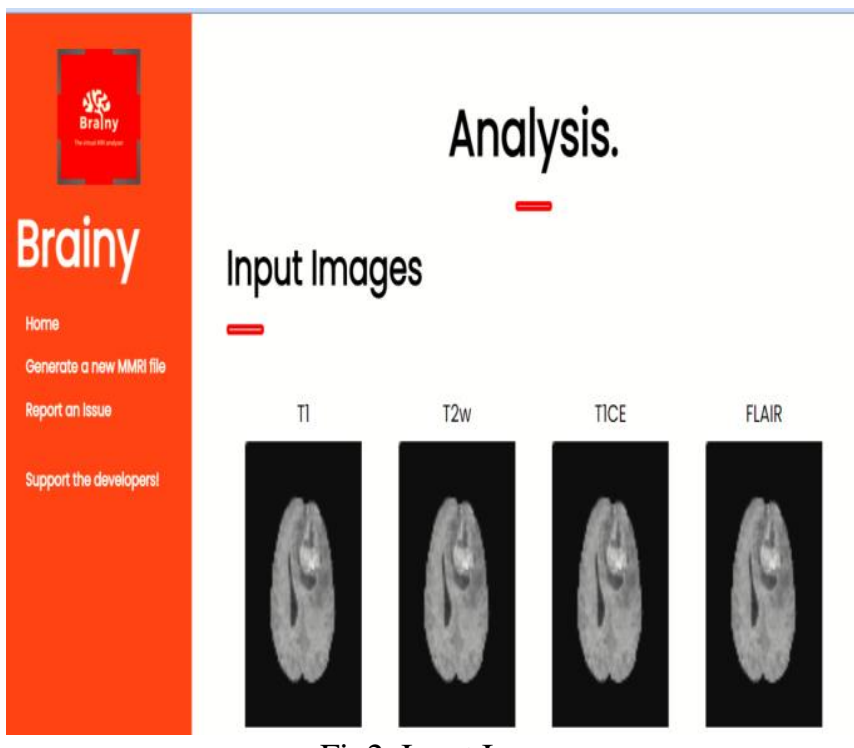

Fig2..Input Images

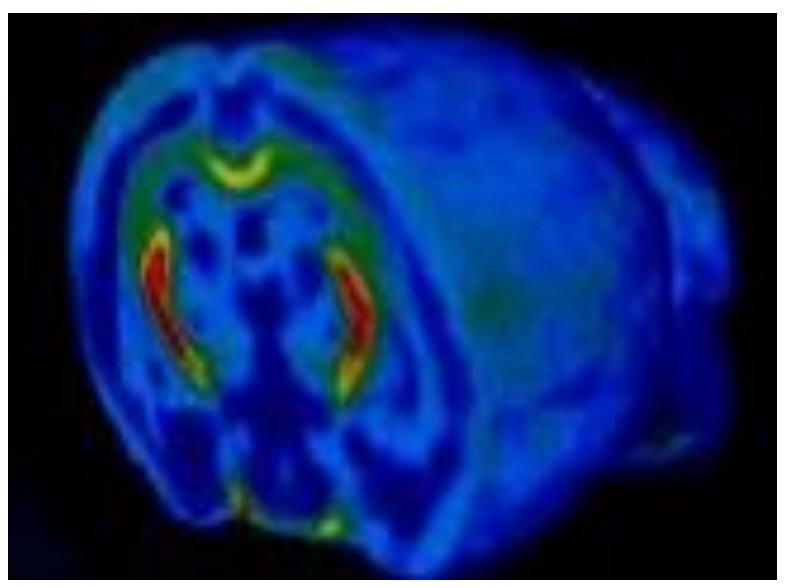

Fig.3. Image of Benign tumor. 


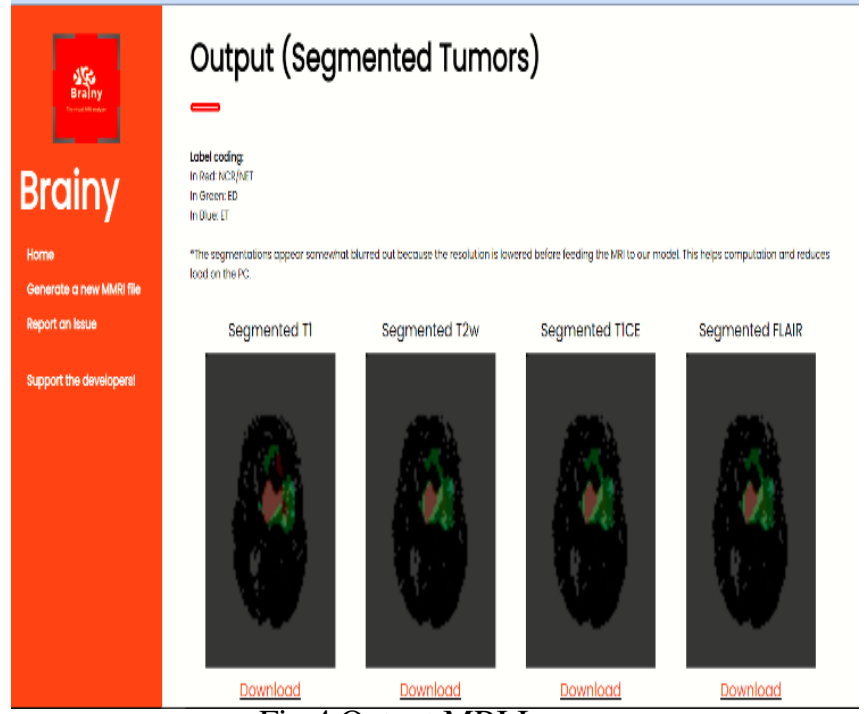

Fig 4.Output MRI Images

\section{CONCLUSION}

In destiny, we plan to make bigger our algorithms to 3dareawhen you consider that we couldn'tdone the modern overall performance with a $2 \mathrm{D}$ community. However, this couldrestrictusing the communitydue to the fact the intensity of the MRI information can alternate. We will evenmake bigger the CRF post-processing with the aid of usingincluding temporal data. Additionally, in a few cases, modern strategies skilled a separate community and proposed a cascaded gadget. Another technique that could enhance the consequences is to pre-teach the community on massive datasets which includes ImageNet. We plan to preteach the downsampling a part of the U-conclusion.

\section{ACKNOWLEDGEMENT}

We are grateful to Mr. J. MAHESH KUMAR, Assistant Professor(E.C.E),for having allowed carrying out this paper work.we take this opportunity to express my profound and whole heartful thanks to our guide, who with his patience support and sincere guidance helped us in the successful completion of the paper.

We would like to thank Dr. B. Srinivasa Raja, Professor and Head of Department (ECE), for valuable suggestions throughout our paper which have helped in giving define shape to this work. We are particularly indebted to him for his innovative ideas, valuable suggestions and guidance during the entire period of work and without his unfathomable energy and enthusiasm, this paper would not have been completed.

We like to express my deep sense of gratitude to Dr. P.M.M.S. Sarma, Principal of GODAVARI INSTITUTE OF ENGINEERING AND TECHNOLOGY(A), for providing us a chance to undergo this paper in a prestigious institute.

\section{REFERENCES}

1. A. KabirAnaraki, M. Ayati, and F. Kazemi, "Magnetic resonance imaging-based brain tumor grades classification and grading via convolutional neural networks and genetic algorithms," Biocybernetics and Biomedical Engineering, vol. 39, no. 1, pp. 63-74, 2019.View at: Publisher Site | Google Scholar.

2. J. Ker, L. Wang, J. Rao, and T. Lim, "Deep learning applications in medical image analysis," IEEE Access, vol. 6, pp. 9375-9389, 2018.View at: Publisher Site | Google Scholar.

3. S. Khan and S.-P. Yong, "A deep learning architecture for classifying medical images of anatomy object," in Proceedings of the 2017 AsiaPacific Signal and Information Processing Association Annual Summit and Conference (APSIPA ASC), pp. 1661-1668, Kuala Lumpur, Malaysia, December 2017.View at: Google Scholar.

4. M. W. Nadeem, M. A. Al Ghamdi, M. Hussain et al., "Brain tumor analysis empowered with deep learning: a review, taxonomy, and future challenges," Brain Sciences, vol. 10, no. 2, pp. 133, 2020. View at: Publisher Site | Google Scholar.

5. "Health in the European Union-facts and figuresStatistics

2019, https://ec.europa.eu/eurostat/statisticsexplained/index.php?title=Health_in_the_Europea n_Union___facts_and_figures.

6. Bureau of Labor Statistics, "Radiologic and MRI Technologists: Occupational Outlook Handbook:: U.S. Bureau of Labor Statistics," United States Department of Labor, 2018, https://www.bls.gov/ooh/healthcare/radiologi c-technologists.htm.

7. A. Işin, C. Direkoğlu, and M. Şah, "Review of MRI-based brain tumor image segmentation using deep learning methods," Procedia Computer Science, vol. 102, pp. 317-324, 2016.View at: Publisher Site | Google Scholar.

8. P. Mlynarski, H. Delingette, A. Criminisi, and N. Ayache, "Deep learning with mixed supervision for brain tumor segmentation," Journal of Medical Imaging, vol. 6, no. 3, p. 1, 2019. View at: Publisher Site | Google Scholar.

9. C. G. Madamombe, "Deep learning techniques to classify and analyze medical imaging data," International Journal of Computational Science and Engineering, vol. 7, no. 4, pp. 109113, 2018. View at: Google Scholar.

10. M. Soltaninejad, G. Yang, T. Lambrou et al., "Supervised learning based multimodal MRI brain tumour segmentation using texture features from supervoxels," Computer Methods and Programs in Biomedicine, vol. 157, pp. 69-84, 2018. View at: Publisher Site | Google Scholar.

11. H. Dong, G. Yang, F. Liu, Y. Mo, and Y. Guo, "Automatic brain tumor detection and segmentation using U-net based fully convolutional networks," Communications in Computer and 
Information Science, vol. 1, pp. 506-517, 2017. View at: Publisher Site | Google Scholar.

12. M. Soltaninejad, G. Yang, T. Lambrou et al., "Automated brain tumour detection and segmentation using superpixel-based extremely randomized trees in flair MRI," International Journal of Computer Assisted Radiology and Surgery, vol. 12, no. 2, pp. 183-203, 2017.View at: Publisher Site | Google Scholar.

13. J. Cheng, "Brain Tumor Dataset", figshare. Dataset,

2017, https://doi.org/10.6084/m9.\%20figshare. 151 2427.v5.

14. J. Cheng, W. Huang, S. Cao et al., "Enhanced performance of brain tumor classification via tumor region augmentation and partition," PLoS One, vol. 10, no. 10, Article ID e0140381, 2015.View at: Publisher Site | Google Scholar.

15. Z. N. K. Swati, Q. Zhao, M. Kabir et al., "Contentbased brain tumor retrieval for MR images using transfer learning," IEEE Access, vol. 7, pp. 1780917822, 2019.View at: Publisher Site | Google Scholar.

16. M. M. Badža and M. C. Barjaktarović, "Classification of brain tumors from mri images using a convolutional neural network," Applied Sciences, vol. 10, no. 6, 2020. View at: $\underline{\text { Publisher }}$ Site | Google Scholar.

17. N. Noreen, S. Palaniappan, A. Qayyum, I. Ahmad, M. Imran, and M. Shoaib, "A deep learning model based on concatenation approach for the diagnosis of brain tumor," IEEE Access, vol. 8, pp. 5513555144, 2020.View at: Publisher Site | Google Scholar.

18. S. Tripathi, A. Verma, and N. Sharma, "Automatic segmentation of brain tumour in MR images using an enhanced deep learning approach," Computer Methods in Biomechanics and Biomedical Engineering: Imaging \& Visualization, pp. 1-10, 2020. View at: Publisher Site | Google Scholar.

19. A. M. Alqudah, H. Alquraan, I. A. Qasmieh, A. Alqudah, and W. Al-Sharu, "Brain tumor classification using deep learning technique - a comparison between cropped, uncropped, and segmented lesion images with different sizes," International Journal of Advanced Trends in Computer Science and Engineering, vol. 8, no. 6, pp. 3684-3691, 2019. View at: Publisher Site | Google Scholar.

20. X. Chen, M Zeng, Y. Tong et al., "Automatic prediction of MGMT status in glioblastoma via deep learning-based MR image analysis," vol. 2020, Article ID 9258649, nine pages, 2020.View at: Publisher Site | Google Scholar. 